\title{
A POTENCIOMETRIA DO AQÜÍFERO BARREIRAS NO SETOR ORIENTAL DA BACIA DO RIO PIRANGI-RN E CONSIDERAÇÕES SOBRE A RELAÇÃO COM MANANCIAIS SUPERFICIAIS
}

\author{
Leandson Roberto F. de Lucena ${ }^{1}$ \\ Ernani Francisco da Rosa Filho ${ }^{1}$ \\ André Virmond Lima Bittencourt ${ }^{1}$
}

\begin{abstract}
RESUMO
O Aqüífero Barreiras representa a principal fonte de abastecimento d'água de diversas cidades do litoral leste do Estado do Rio Grande do Norte, incluindo a capital Natal. A bacia do Rio Pirangi também contribui para o abastecimento de alguns municípios sob os seus domínios, inclusive a zona sul de Natal. Entretanto, observa-se uma carência de estudos hidrológicos subterrâneos e superficiais que contemplem a bacia do Rio Pirangi, ao contrário do que ocorre com a área adjacente sul desta, o sistema lacustre do Bonfim, e norte, a região metropolitana de Natal. O presente artigo expõe os resultados obtidos com a elaboração do mapa potenciométrico do Aqüífero Barreiras no setor oriental da bacia do Rio Pirangi. Este levantamento evidenciou a presença de uma zona de recarga principal na região da sede municipal de Parnamirim, além de outra ao sul, adjacente ao limite da referida bacia. Esta segunda zona de recarga caracterizou uma importante conexão hidráulica entre o sistema lacustre do Bonfim e a bacia do Pirangi. A descarga do aqüífero verifica-se no baixo curso do Riacho Ponte Velha (Rio Pitimbú), incluindo a Lagoa do Jiqui, Riacho Taborda, além do Rio Pirangi. A potenciometria mostra igualmente uma ampla relação entre os mananciais subterrâneos e superficiais, sendo o aqüífero nitidamente de regime influente nos canais fluviais e espelhos d'água, com destaque para a Lagoa do Pium.
\end{abstract}

Palavras-chave: Aqüífero Barreiras, bacia do Rio Pirangi, mapa potenciométrico.

\begin{abstract}
The Barreiras Aquifer is the main water supplier to several cities in the Rio Grande do Norte State, NE Brazil, including its capital, Natal. The Pirangi River Basin also contributes to the water supply for the southern region of Natal and several peripherical cities. However, there is a lack of underground and surface hydrological studies in the Pirangi River Basin. The opposite occurs with other area like: the Bonfim lacustrine system, the northern region of Natal and its main urban area. The present paper shows results obtained with the elaboration of the piezometric map of the eastern sector of the Pirangi River Basin. This map highlightened the presence of two main recharge zones: one near to the town of Parnamirim and another one next to the limits of the basin itself. This second recharge zone is an important hydraulic connection beween the Bonfim lacustrine system and the Pirangi River Basin. The Aquifer discharge is found to be downstream the Ponte Velha Brook (Pitimbu River) and also includes the Jiqui Lagoon, Taborda Brook and Pirangi River itself. The piezometric map also shows the relationship between the surface and underground water systems. In this case, the underground aquifer clearly influences the river channels and water bodies in the region, like the Pium Lagoon.
\end{abstract}

Key-words: Barreiras Aquifer, Pirangi River Basin, piezometric map.

${ }^{1}$ LPH-UFPR, Centro Politécnico - Jd. Das Américas - 81531-990 - Curitiba-PR. Fone/Fax: (41)267-7910. 


\section{1 - INTRODUÇÃO E OBJETIVOS}

A elaboração de um mapa potenciométrico representa um dos principais estudos de natureza hidrogeológica física a ser desenvolvido numa determinada área de ocorrência de um aqǘfero. Através desse mapa, possibilita-se o conhecimento de zonas de descarga, recarga e trânsito do aqǘfero, sentido do fluxo subterrâneo principal e fluxos secundários, áreas com maior ou menor transmissividade, dentre outras informações não menos importantes.

A região ora estudada situa-se a sul da cidade de Natal-RN, litoral leste do Estado do Rio Grande do Norte-Brasil, abrangendo o setor oriental da bacia do Rio Pirangi e envolvendo parte dos municípios de Parnamirim, Nísia Floresta e São José de
Mipibú-RN (figura 1). O interesse na bacia do Rio Pirangi explica-se pelo fato desta exercer papel fundamental no abastecimento d'água da zona sul da cidade de Natal, apesar da carência de estudos hidrológicos nesta área. Somado a isso, busca-se fechar uma lacuna existente entre o sistema lacustre do Bonfim (ao sul) e a região metropolitana de Natal (ao Norte), as quais já foram contempladas com diversas pesquisas, sobretudo de caráter hidrogeológico. Dessa forma, o presente trabalho objetiva evidenciar características do mapa potenciométrico do Aqǘfero Barreiras no setor oriental da bacia do Rio Pirangi, com vistas a fornecer subsídios aos órgãos governamentais gestores no sentido de planejar a utilização racional deste manancial.

Figura 1 - Localização da área.

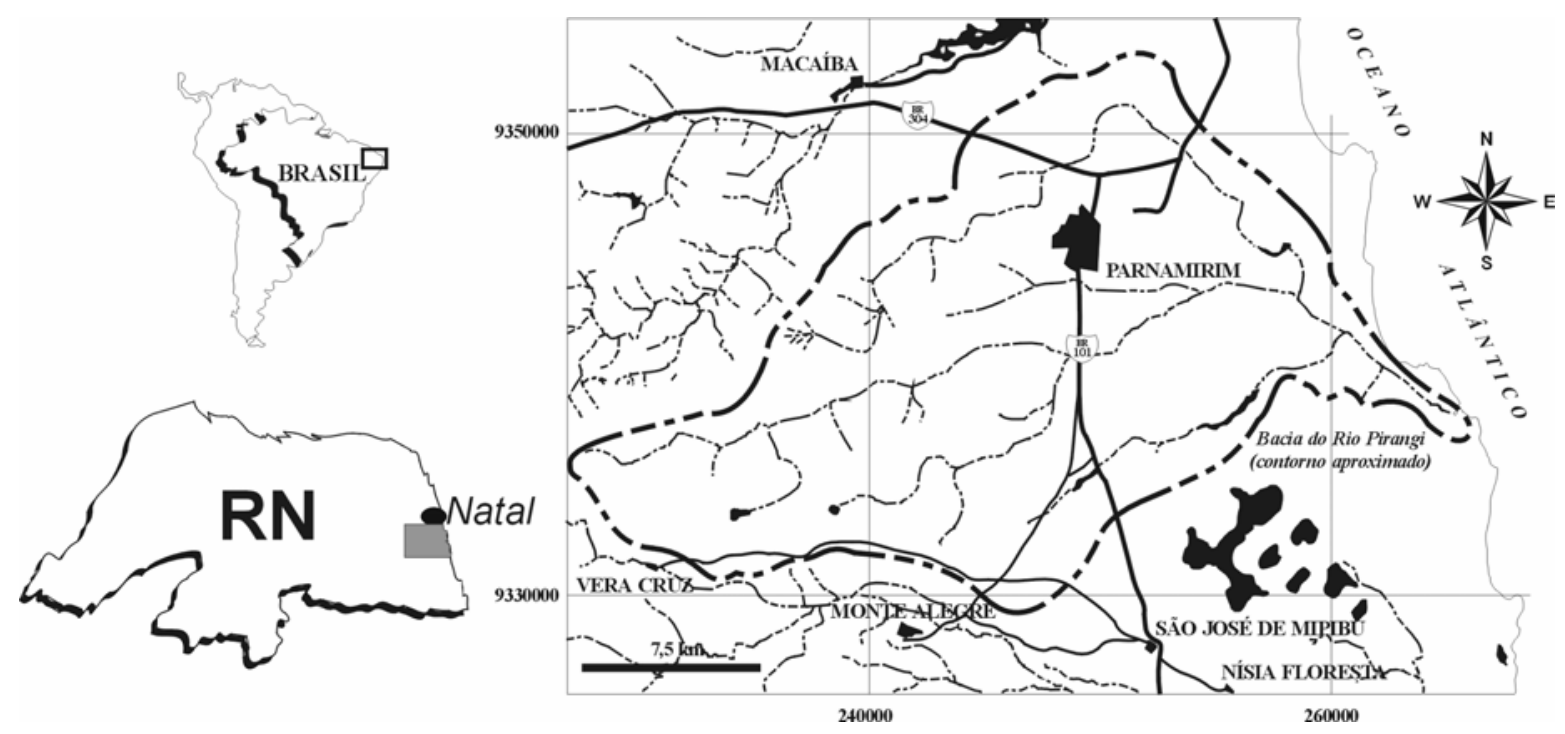

\section{2 - CARACTERÍSTICAS DA GEOLOGIA E HIDROGEOLOGIA DA ÁREA}

A geologia da área é constituída estratigraficamente pelo embasamento cristalino Pré-cambriano, sotoposto a sedimentos cretácicos (este constituído por uma sequêencia arenítica basal e outra carbonática no topo) e capeados por unidades cenozóicas, na qual apenas estas últimas são aflorantes. Dentre estas unidades cenozóicas, destacam-se o Grupo Barreiras (de idade Terciária-Quaternária) e toda a sedimentação quaternária, composta por diversas gerações de dunas, coberturas arenosas, bem como sedimentos praiais e aluvionares. $\mathrm{O}$ arcabouço tectono-estrutural 20 é formado por uma complexa estruturação regional (Bezerra et al, 1993; Lucena \& Queiroz, 1996; Coriolano et al, 1998), caracterizada em três direções principais: NW, NE e E-W, aproximadamente, além de uma quarta direção, menos expressiva e não individualizada em escala de mapa, com orientação geral N-S. Estas direções estruturais foram denominadas de alinhamentos morfotectônicos ou mesmo falhamentos, quando possível a quantificação de rejeitos e/ou feições apropriadas no terreno.

O contexto hidrogeológico alvo do presente estudo é representado pelo Aqüífero Barreiras. Este último, de caráter 
local livre a semi-confinado, é responsável pelo abastecimento da maioria das cidades da faixa litorânea oriental do Estado, incluindo a capital Natal. Apresenta-se, sob o ponto de vista litológico, bastante heterogêneo, envolvendo desde arenitos pouco argilosos a conglomeráticos, até argilas. Esta composição diversificada, somada à variações de espessuras saturadas (geralmente decorrentes do arcabouço tectono-estrutural da área), resulta em vazões explotáveis igualmente variáveis, em geral da ordem de $5 \mathrm{~m}^{3} / \mathrm{h}$ a $100 \mathrm{~m}^{3} / \mathrm{h}$. O limite inferior deste aqüífero é o topo da seqüência carbonática mesozóica não aflorante da região, a qual foi individualizada nas perfurações como sendo constituído por sedimentos areno-argilosos a argilosos de composição calcífera e baixa potencialidade hidrogeológica, ou mesmo o embasamento cristalino, nas áreas próximas do contato deste último com a bacia sedimentar costeira.

\section{3 - METODOLOGIA GERAL}

A metodologia geral de trabalho compreendeu basicamente aqueles procedimentos clássicos aplicados na elaboração de um mapa potenciométrico de uma dada região (Castany, 1975). Inicialmente foi realizado um cadastro de poços do setor oriental da bacia do Rio Pirangi, com posterior identificação dos mesmos em campo e checagem se estes, dentre outra características, encontravam-se inseridos verticalmente no Aqüífero Barreiras. As captações selecionadas foram então submetidas a um nivelamento topográfico tipo geométrico (nivelamento e contra-nivelamento). $\quad \mathrm{O}$ equipamento utilizado foi um nível automático SOKISHA (mod. 19754-B-Z), sendo os poços referenciados em relação ao RN (referência de nível) 1829 do IBGE (Instituto Brasileiro de Geografia e Estatística), situado no degrau lateral da igreja católica matriz da cidade de Parnamirim-RN na praça João Paulo II.

Estes poços foram submetidos a duas medições de nível, sendo uma ao final do período chuvoso e outra ao final do período de estiagem, com vistas a obtenção de possíveis variações das equipotenciais e eventuais inversões locais do fluxo subterrâneo.

\section{4 - RESULTADOS E DISCUSSÃO}

A presente potenciometria foi elaborada a partir de levantamentos realizados no setor oriental da bacia, conforme reportado, tendo em vista um esperado aumento das relações águas superficiais $x$ águas subterrâneas nesta área. Este mapa possuiu como objetivos primordiais a delimitação/individualização de zonas de recarga e descargas das águas subterrâneas locais, situar as lagoas do Jiqui e Pium no contexto hidrogeológico regional e definir as principais frentes de escoamento. O mapa potenciométrico da figura 2, elaborado ao final da estação seca (março de 2001), evidenciou as principais características peculiares da região, incluindo algumas surpresas. Em termos de zonas de recarga, duas importantes subáreas foram diferenciadas e a partir das quais originam-se as principais frentes de escoamento subterrâneo. A primeira situase na altura da cidade de Parnamirim, fato que denota alguma preocupação face às condições deficitárias de saneamento básico na cidade e a presença de determinados "lixões", especificamente um localizado nas proximidades do final da margem direita da pista do aeroporto internacional Augusto Severo (margem da RN-066 - Rodovia Trampolim da Vitória). A outra grande zona de recarga acha-se proveniente do Sistema Lacustre do Bonfim (Nísia Floresta-RN), constituindo-se num aspecto bastante relevante e confirmando um outro levantamento realizado por Lucena et al (2002) entre este sistema lacustre e a bacia do Rio Pirangi. Tal importância resulta do fato de que estudos prévios realizados na área da Lagoa do Bonfim (Costa, 1997), destinados ao conhecimento da disponibilidade hídrica desta área tendo em vista o sistema de adução Agreste-Trairi do Governo do Estado, não mostra esta conexão hidráulica. O sistema do Bonfim, até então considerado como praticamente endorrêico sob o ponto de vista subterrâneo, deve ser reavaliado, principalmente 0 contexto geológico do limite com a bacia do Pirangi e as respectivas conexões hidráulicas entre os dois sistemas.

A grande zona de descarga abrange o "binômio" Rio Pitimbu - Taborda/Pirangi, incluindo a Lagoa do Jiqui. Esta observação eleva-se em importância, a exemplo da área de recarga de Parnamirim, uma vez que a referida lagoa abastece boa parte da zona 
sul de Natal (aproximadamente $40 \%$ de toda a água encanada). devendo, portanto, receber especial atenção no tocante às suas margens e contexto subterrâneo adjacente, sobretudo em termos qualitativos (monitoramento da qualidade da água de poços nas vizinhanças, por exemplo).

Uma outra observação não menos importante diz respeito ao considerável espaçamento entre as isopiezas em determinados locais, refletindo baixos gradientes hidráulicos (da ordem de $10^{-3}$ ), favorecendo as condições de recarga, enquanto que valores relativamente elevados são mostrados nas áreas de descarga do aqüífero, sobretudo no baixo curso do Rio Pirangi (gradientes hidráulicos da ordem de $10^{-2}$ ).

Uma segunda potenciometria é apresentada na figura 3 , com base em dados coletados ao final do período chuvoso (agosto de 2000), objetivando confrontar os dois mapas e identificar possíveis alterações do contexto já explicitado. Tal levantamento, no entanto, não evidenciou maiores diferenças daqueles resultados mostrados no mapa da figura 2. As exceções ficam por conta de uma pequena tendência de aumento das áreas das zonas de recarga de Parnamirim e sistema lacustre do Bonfim, além do incremento da configuração da zona de descarga regional (rios Pitimbu e Taborda nos seus baixos cursos). Outra mudança foi observada na altura da Lagoa do Pium, com uma pequena inversão de fluxo subterrâneo na sua margem esquerda. A disposição das equipotenciais neste local demonstra uma superfície potenciométrica inclinada, com caimento para NNE, ocasionando o aspecto de aqüífero influente de sul para nortenordeste e afluente neste mesmo sentido a partir da lagoa. Esta configuração deve ser decorrente do aumento do aporte subterrâneo proveniente da área de recarga do sistema do Bonfim durante o período chuvoso. Afora este caso, não foi observado outras inversões significativas de fluxos.

Uma proeminente feição que se mostra em ambos os mapas diz respeito a uma área situada no quadrante SW da área, delimitada aproximadamente pela equipotenciais de 32 e 24 (na figura 2) e 28 e 24 (na figura 3). Tal área é indicativa de um aumento da transmissividade local, estando associada com o aumento de espessura saturada decorrente de falhamentos (Lucena \& Queiroz, 1996; Lucena et al, 1999).

No tocante aos limites subterrâneos, além da não caracterização do limite da bacia com o Sistema do Bonfim ao sul, não se observou limites regionais proeminentes. 
Figura 2 - Mapa potenciométrico do Aqüífero Barreiras no setor oriental da bacia do Rio Pirangi, elaborado ao final do período de estiagem da região (março de 2001).

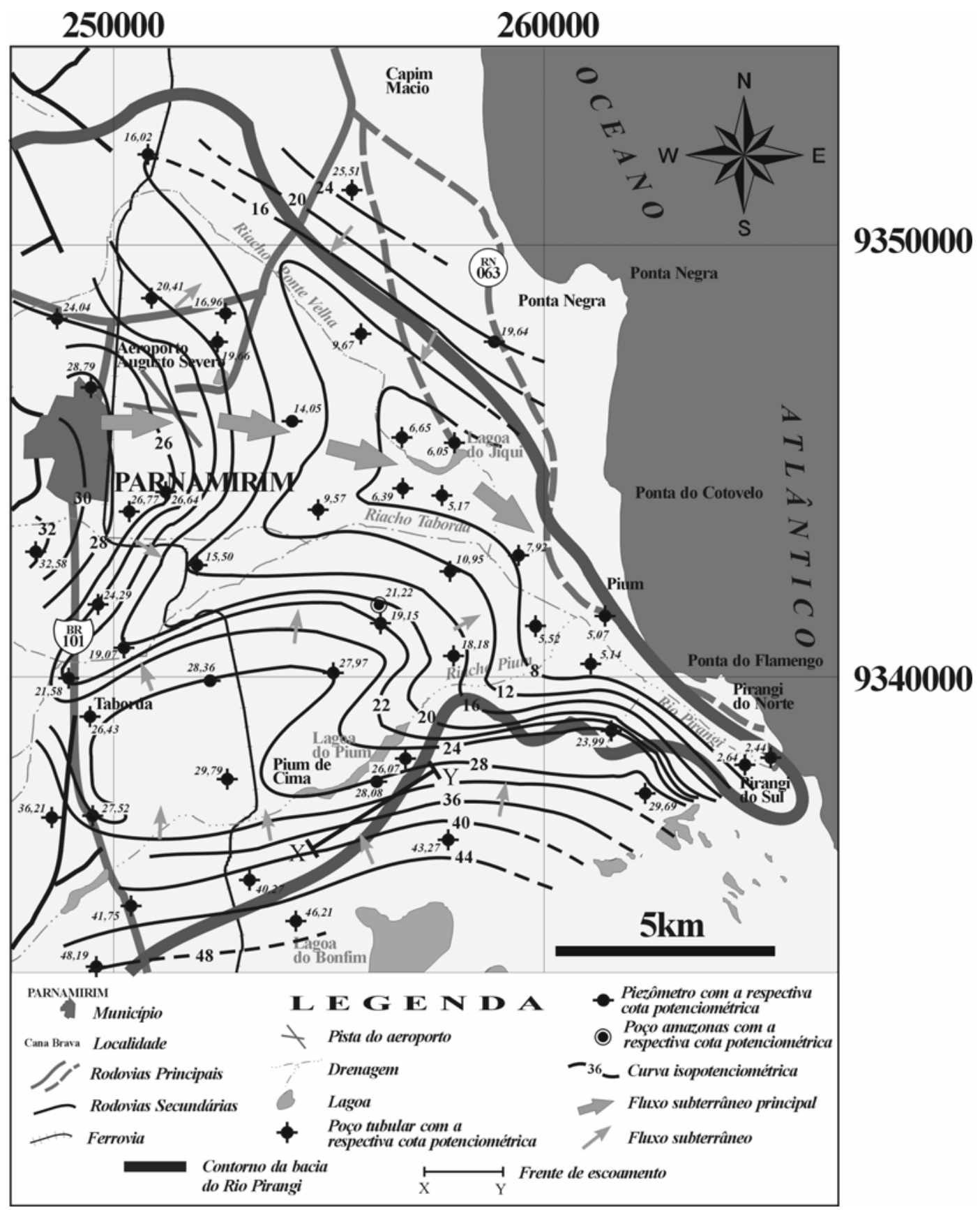


Figura 3 - Mapa potenciométrico do Aqüífero Barreiras no setor oriental da bacia do Rio Pirangi, elaborado ao final do período chuvoso da região (agosto de 2000).

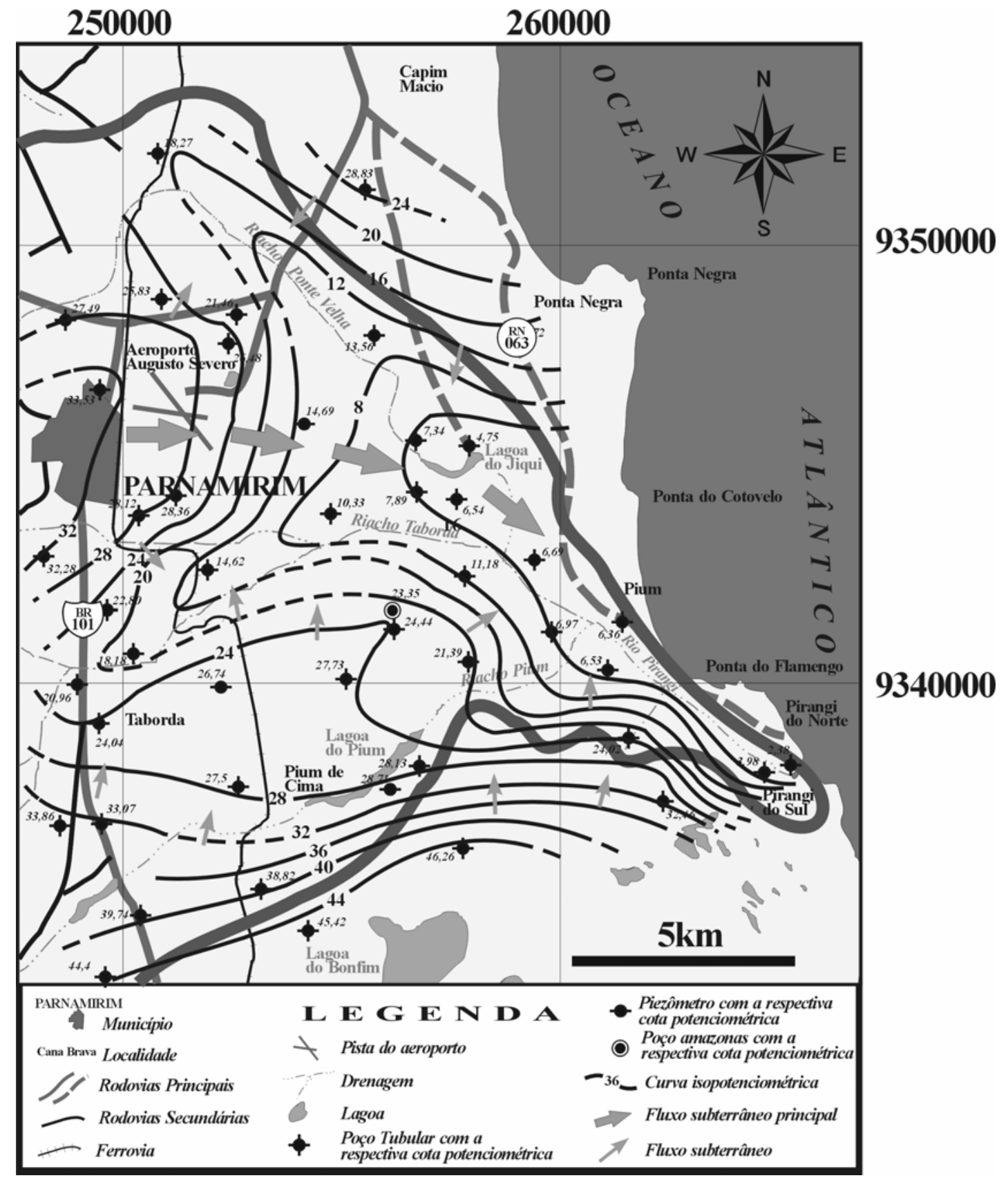

\section{5 - CONSIDERAÇÕES SOBRE A RELAÇÃO COM MANANCIAIS SUPERFICIAIS}

Em termos gerais, o aqüífero apresenta relação de influência com todo o contexto hídrico superficial, incluindo as lagoas do Jiqui e Pium, rios e riachos da área. A exceção deve ser creditada tão somente a um curto período de tempo, invariavelmente logo após a consolidação do período chuvoso no litoral leste do Rio Grande do Norte (Maio-Junho), conforme observado na figura 4. Esta observação decorre do intervalo de tempo entre o aumento do volume d'água dos rios e riachos, proporcionado pela precipitação direta sobre estas drenagens, e a resposta posterior do aqüífero às chuvas (subida da superfície potenciométrica). 
Figura 4 - Distribuição pluviométrica nos meses de janeiro de 2000 a outubro de 2001, posto pluviométrico da base física da Empresa de Pesquisa Agropecuária do Rio Grande do Norte-EMPARN em Parnamirim-RN, situado na margem direita da Lagoa do Jiqui.

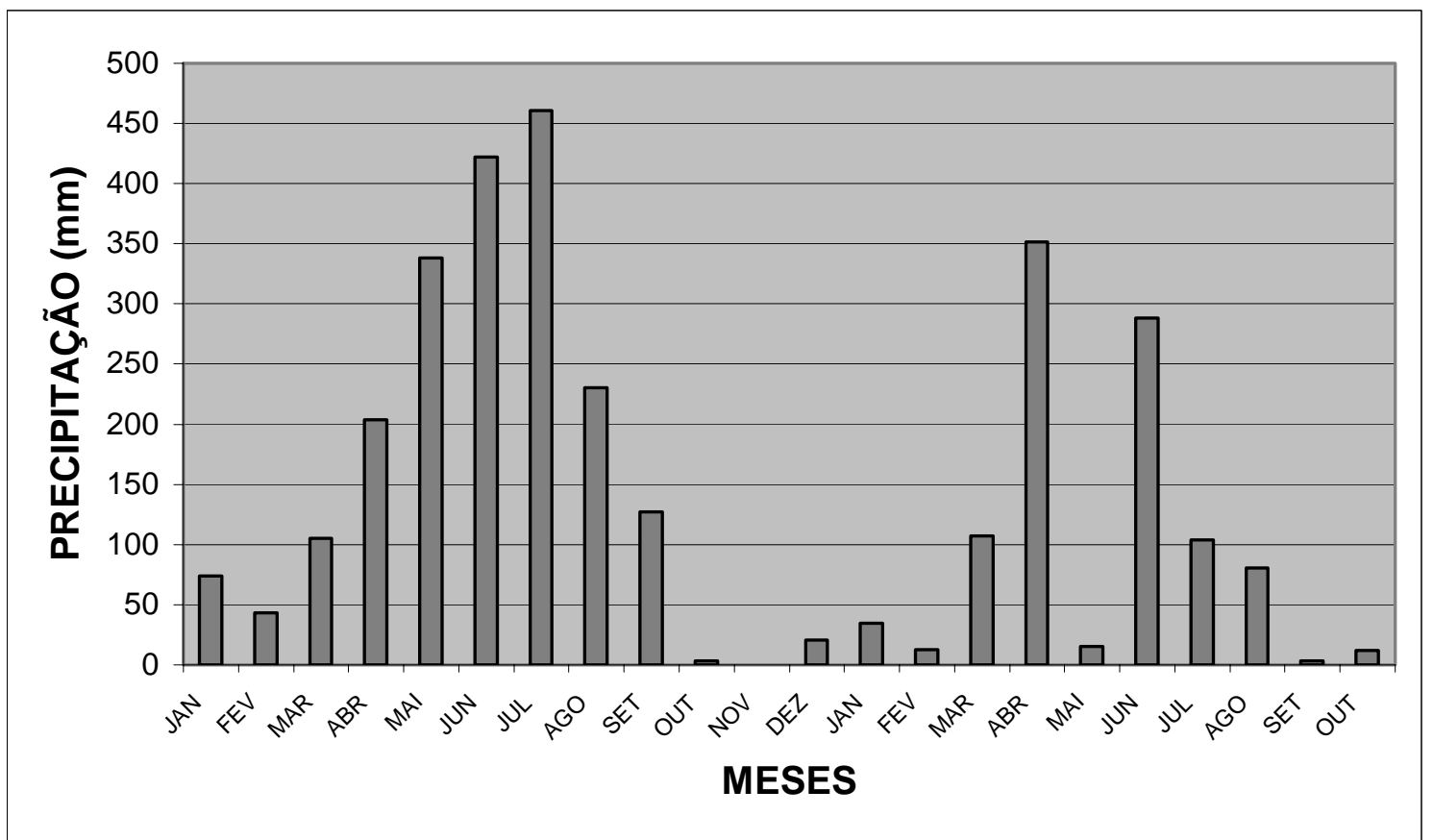

Algumas medições de descargas fluviométricas foram realizadas (tabela 1), com destaque para as entradas e saídas das lagoas do Pium e Jiqui, respectivamente nos riachos Pium e Ponte Velha (Rio Pitimbu), além do Rio Pirangi (output da bacia). Estas medidas foram obtidas através da utilização de micro-molinetes, sendo um digital da Global Water Instrumentation modelo FP101/202 e outro da General Oceanics modelo 2030R.

Tabela 1 - Evolução mensal de descargas fluviométricas entre os meses de Fevereiro de 2000 a Dezembro de 2001.

\begin{tabular}{|c|c|c|c|c|c|}
\hline \multirow{2}{*}{$\begin{array}{c}\text { MED. MENSAIS } \\
\left.\text { Q (m }{ }^{3} / \mathrm{s}\right)\end{array}$} & $\begin{array}{c}\text { ESTAÇÕES FLUVIOMÉTRICAS } \\
\text { (in Lagoa } \\
\text { Jiqui) }\end{array}$ & $\begin{array}{c}\text { Rio Pitimbu } \\
\text { (out Lagoa } \\
\text { Jiqui) }\end{array}$ & $\begin{array}{c}\text { Rch. Pium } \\
\text { (in Lagoa } \\
\text { Pium) }\end{array}$ & $\begin{array}{c}\text { Rch. Pium } \\
\text { (out Lagoa } \\
\text { Pium) }\end{array}$ & Rio Pirangi \\
\hline JANEIRO/2000 & - & - & - & - & - \\
\hline FEVEREIRO/2000 & - & - & - & - & 1,3705 \\
\hline MARÇO/2000 & 0,4267 & - & 0,0784 & 0,3085 & 1,1409 \\
\hline ABRIL/2000 & 0,7486 & 0,3226 & 0,1258 & 0,4290 & 2,2908 \\
\hline MAIO/2000 & 0,8054 & 0,4820 & 0,1429 & 0,2021 & 2,5576 \\
\hline JUNHO/2000 & 3,3254 & 3,2569 & 0,1678 & 0,8336 & - \\
\hline JULHO/2000 & 3,0253 & - & 0,2501 & 1,0839 & 6,9656 \\
\hline AGOSTO/2000 & 2,8795 & 2,6549 & 0,3420 & 1,4226 & 7,8391 \\
\hline SETEMBRO/2000 & 3,3387 & 3,1438 & 0,4017 & 1,2336 & 7,5157 \\
\hline OUTUBRO/2000 & 2,4768 & 2,2181 & 0,3896 & 1,0702 & 5,5374 \\
\hline
\end{tabular}




\begin{tabular}{|c|c|c|c|c|c|}
\hline \multirow{2}{*}{$\begin{array}{c}\text { MED. MENSAIS } \\
\text { Q (m }{ }^{3} / \mathrm{s} \text { ) }\end{array}$} & $\begin{array}{c}\text { Rio Pitimbu } \\
\text { (in Lagoa } \\
\text { Jiqui) }\end{array}$ & $\begin{array}{c}\text { Rio Pitimbu } \\
\text { (out Lagoa } \\
\text { Jiqui) }\end{array}$ & $\begin{array}{c}\text { Rch. Pium } \\
\text { (in Lagoa } \\
\text { Pium) }\end{array}$ & $\begin{array}{c}\text { Rch. Pium } \\
\text { (out Lagoa } \\
\text { Pium) }\end{array}$ & Rio Pirangi \\
\hline NOVEMBRO/2000 & 2,3982 & 2,0076 & 0,3605 & 1,0362 & 5,4746 \\
\hline DEZEMBRO/2000 & 2,06874 & 1,82837 & 0,32799 & 0,92808 & 4,92328 \\
\hline JANEIRO/2001 & - & - & 0,33094 & - & - \\
\hline FEVEREIRO/2001 & - & - & - & - & - \\
\hline MARÇO/2001 & 2,02583 & 1,48393 & 0,31107 & 1,17835 & 6,95664 \\
\hline ABRRIL/2001 & 1,66649 & 1,48886 & 0,38560 & 0,73313 & 4,62655 \\
\hline MAOI/2001 & 1,34412 & 0,90022 & 0,25743 & 0,70395 & 3,21716 \\
\hline JUNHO/2001 & 1,59480 & 1,36667 & 0,17793 & 0,74822 & 3,60115 \\
\hline JULHO/2001 & 1,45440 & 0,90392 & 0,11353 & 0,51002 & 3,45646 \\
\hline AGOSTO/2001 & 1,12501 & 0,81524 & 0,09799 & 0,41457 & 3,07435 \\
\hline SETEMBRO/2001 & 1,04101 & 0,60978 & 0,08546 & 0,34740 & 2,50390 \\
\hline OUTUBRO/2001 & 0,90082 & 0,51586 & 0,08632 & 0,33901 & 2,55696 \\
\hline NOVEMBRO/2001 & 0,79617 & 0,37974 & 0,14810 & 0,20684 & 2,09665 \\
\hline DEZEMBRO/2001 & 0,80006 & 0,37312 & 0,10703 & 0,28344 & 2,30853 \\
\hline
\end{tabular}

Os valores relativos às descargas do Rio Pirangi (output da bacia), confrontados com a pluviometria no período (ver figura 4), podem fornecer uma idéia inicial do fluxo de base máximo, responsável pelo regime perene do referido canal e de todo o setor leste desta bacia de drenagem. Tomandose como referência o período de Janeiro de 2000 a Janeiro de 2001 (considerando este um ano de distribuição pluviométrica próxima da normal para a região), além de dados imediatamente anteriores a este intervalo, com valores de precipitação nulos ou inferiores a $10 \mathrm{~mm}$ conforme o setor de meteorologia da EMPARN, as descargas observadas em Fevereiro e Março de 2000 (ver tabela 1) podem ser encaradas como sendo do período de recessão do rio. Dessa forma, pode-se dizer que o escoamento do Rio Pirangi durante este período é associado ao fluxo de base proveniente do Aqüífero Barreiras. Projetando-se a descarga medida no mês de Março/2000 $\left(1,14 \mathrm{~m}^{3} / \mathrm{s}\right)$ e adotando-se um coeficiente de recessão de $0,05 \mathrm{dia}^{-1}$ na equação de recessão de um rio $\left(\mathrm{Q}_{\mathrm{t}}=\mathrm{Q}_{0} \exp -\alpha \mathrm{t}\right.$, in Feitosa \& Manoel Filho, 1997), a descarga relativa ao fluxo de base, decorridos 30 dias após a cessão do evento de recarga, seria da ordem de $0,25 \mathrm{~m}^{3} / \mathrm{s}$.

As principais lagoas da área, Jiqui e Pium, acham-se igualmente conectada hidraulicamente com o sistema aqüífero. A Lagoa do Jiqui situa-se no início da grande zona de descarga subterrânea regional (ver figuras 2 e 3), atuando assim como exutório natural do Aqüífero Barreiras no setor nortenordeste da bacia do Rio Pirangi. Já a Lagoa do Pium, mostra-se como um reservatório bastante sigular, sobretudo em relação às suas descargas medidas de entrada (in) e saída (out) apresentadas na tabela 1. Estas últimas são sistematicamente maiores de que as vazões de entrada, sem que seu volume acumulado não sofra variações consideráveis, de acordo com observações linimétricas diárias efetuadas ao longo do biênio 2000-2001. Por outro lado, Lucena et al (2002) caracterizou uma importante conexão hidráulica subterrânea entre o sistema lacustre do Bonfim (ao sul) e a bacia do Rio Pirangi, na altura da Lagoa do Pium. Esta conexão é resultado do aumento brusco 
local da espessura do Aqüífero Barreiras decorrente de falhamentos, somado à presença de cotas potenciométricas relativamente maiores a norte da Lagoa do Bonfim. Esta conjunção de fatores origina um fluxo subterrâneo proveniente do sistema Bonfim e no sentido da Lagoa do Pium, sendo responsável pela relativa regularização da descarga na lagoa, além de se constituir numa área de recarga de toda a bacia do Rio Pirangi. Em termos quantitativos, pode-se estimar esta contribuição subterrânea através da expressão (Feitosa \& Manoel Filho, 1997):

$$
\mathrm{Q}=\mathrm{T} \text { i I }
$$

Adotando-se uma transmissividade de $5,5 \mathrm{~m}^{2} / \mathrm{h}$ (modificado de Costa, 1997), um gradiente hidráulico de 0,0108 (avaliado no mapa da figura 2) e uma frente de escoamento de 3780 metros (figura 2), a descarga subterrânea que aporta na margem direita da Lagoa do Pium, proveniente do sistema Bonfim, é de aproximadamente $224 \mathrm{~m}^{3} / \mathrm{h}$.

\section{6 - SÍNTESE CONCLUSIVA}

A potenciometria do Aqüífero Barreiras no setor oriental da bacia do Rio Pirangi evidenciou a existência de uma zona de recarga principal, situada na área da sede municipal de Parnamirim e uma secundária, situada ao norte da Lagoa do Bonfim (no limite sul da bacia), enquanto que a zona de descarga regional é compreendida pela região dos baixos cursos dos riachos Ponte Velha/Rio Pitimbu (incluindo a Lagoa do Jiqui) e Taborda e Rio Pirangi. Os gradientes hidráulicos apresentam-se relativamente menores nestas zonas de recarga, da ordem de $10^{-3}$, atingindo valores em torno de $10^{-2}$ nas área de descarga do aqüífero, principalmente no baixo curso do Rio Pirangi.

Toda a área pesquisada evidencia uma ampla relação entre mananciais subterrâneos do Aqüífero Barreiras e superficiais. O regime perene dos canais fluviais locais é creditado ao caráter influente do aqüífero. Esta influência é igualmente evidenciada sobre as duas principais lagoas da área, Jiqui e Pium, sendo esta última aproximadamente regularizada, sob o ponto de vista de volume armazenado, decorrente da contribuição subterrânea proveniente do sistema do Bonfim.

\section{7 - REFERÊNCIAS BIBLIOGRÁFICAS}

BEZERRA, F. H. R.; LUCENA, L. R. F. DE; SAAD, A.; MOREIRA, J. A. M.; LINS, F. A. P. L.; NOGUEIRA, A. M. B.; MACEDO, J. W. P.; NAZARÉ JR. D. 1993. Estruturação neotectônica do litoral de Natal-RN, com base na correlação entre dados geológicos, geomorfológicos e gravimétricos. In: SIMPÓSIO NACIONAL DE ESTUDOS TECTÔNICOS, IV. 1993, Belo Horizonte. Anais. Belo Horizonte-MG. SBG, Núcleo MG. Bol. 12: p. 317-321.

CASTANY, G. 1975. Prospección y explotación de las aguas subterráneas. Barcelona. Ed. Omega. $738 \mathrm{p}$.

CORIOLANO, A.C.F.; LUCENA, L.R.F.; JARDIM DE SÁ, E.F.; SAADI, A. 1998. A deformação quaternária no litoral oriental do Rio Grande do Norte. In: SIMPÓSIO NACIONAL DE ESTUDOS TECTÔNICOS, VIII. Lençóis, 1997. Anais... Lençóis-BA, SBG. P. 67-70.

COSTA, W.D. 1997. Estudo da disponibilidade hídrica da Lagoa do Bonfim. In: SRH-RN. Costa Consultoria e Serviços Técnicos e Ambientais, Natal. $83 \mathrm{p}$.

FEITOSA, F.A.C. \& MANOEL FILHO. 1997. Hidrogeologia - conceitos e aplicações. Fortaleza, CPRM/REFO, LABHID-UFPE. $2^{\mathrm{a}}$ ed. $391 \mathrm{p}$.

LUCENA, L.R.F.; OLIVEIRA, S.K.; MEDEIROS, W.E.. 1999. Condicionamento estrutural sobre 0 Aqüífero Barreiras e Sistema Lacustre do Bonfim, Nísia Floresta-RN. In: INTERNATIONAL CONGRESS OF THE BRASILIAN GEOPHYSICAL SOCIETY, VI. Rio de Janeiro, 1999. Anais em CD. Rio de Janeiro-RJ, SBGf.

LUCENA, L.R.F. \& QUEIROZ, M.A. 1996. Considerações sobre as influências de uma tectônica cenozóica na pesquisa e prospecção de recursos hídricos - o exemplo do litoral sul de Natal-RN, Brasil. Revista Águas Subterrâneas, ABAS. Vol. 1, n 15: 81-88.

LUCENA, L.R.F.; ROSA FILHO, E.F.; HINDI, E.C. 2002. O fator estrutural atuante na conexão hidráulica subterrânea entre 0 sistema lacustre do Bonfim e a bacia do Rio Pirangi, litoral leste do Rio Grande do Norte. Revista Águas Subterrâneas, ABAS. $N^{\circ}$ 16: 69-75. 
Rev. Águas Subterrâneas nํ18/ Janeiro 2004 